\title{
Inhibition of soluble epoxide hydrolase attenuates eosinophil recruitment and food allergen-induced gastrointestinal inflammation
}

\author{
Idil Bastan ${ }^{\star}$, Xiao Na Ge ${ }^{\dagger}$, Mythili Dileepan $^{\dagger}$, Yana G. Greenberg ${ }^{\dagger}$, Alonso G. Guedes ${ }^{\star}$, Sung \\ He Hwang ${ }^{\ddagger}$, Bruce D. Hammock ${ }^{\ddagger}$, Robert J. Washabau*, Savita P. Rao ${ }^{\dagger, 1}$, and P. \\ Sriramarao ${ }^{\dagger, 1}$ \\ *Department of Veterinary Clinical Sciences, University of Minnesota, St. Paul, MN 55108, USA \\ tDepartment of Veterinary and Biomedical Sciences, University of Minnesota, St. Paul, MN \\ 55108, USA \\ ‡Department of Entomology, Nematology and Comprehensive Cancer Center, University of \\ California, Davis, CA 95616
}

\begin{abstract}
Prevalence of food allergies in the US is on the rise. Eosinophils are recruited to the intestinal mucosa in substantial numbers in food allergen-driven gastrointestinal (GI) inflammation. Soluble epoxide hydrolase (sEH) is known to play a pro-inflammatory role during inflammation by metabolizing anti-inflammatory epoxyeicosatrienoic acids (EETs) to pro-inflammatory diols. We investigated the role of $\mathrm{sEH}$ in a murine model of food allergy and evaluated the potential therapeutic effect of a highly selective sEH inhibitor ( $t$-TUCB). Oral exposure of mice on a soyfree diet to soy protein isolate (SPI) induced expression of intestinal $\mathrm{sEH}$, increased circulating total and antigen-specific IgE levels and caused significant weight loss. Administration of $t$-TUCB to SPI-challenged mice inhibited IgE levels and prevented SPI-induced weight loss. Additionally, SPI induced GI inflammation characterized by increased recruitment of eosinophils and mast cells, elevated eotaxin-1 levels, mucus hypersecretion and decreased epithelial junction protein expression. In $t$-TUCB-treated mice, eosinophilia, mast cell recruitment and mucus secretion were significantly lower than in untreated mice and SPI-induced loss of junction protein expression was prevented to variable levels. sEH expression in eosinophils was induced by inflammatory mediators TNF- $a$ and eotaxin-1. Treatment of eosinophils with $t$-TUCB significantly inhibited eosinophil migration, an effect which was mirrored by treatment with 11,12-EET, by inhibiting intracellular signaling events such as ERK (1/2) activation and eotaxin-1-induced calcium flux.
\end{abstract}

\footnotetext{
${ }^{1}$ Corresponding author information: P. Srirama Rao, University of Minnesota, 1971 Commonwealth Avenue, St. Paul, MN 55108, Phone: 612-625-5163, psrao@umn.edu; Savita P. Rao, University of Minnesota, 1971 Commonwealth Avenue, St. Paul, MN 55108, Phone: 612-626-5288, raoxx099@umn.edu.

Authorship

P.S., S.P.R., R.J.W., designed the research. I.B., X.N.G., M.D., and Y.G.G performed the experiments. I.B., X.N.G., M.D., Y.G.G. and S.P.R. analyzed the results. A.G.G and B.D.H. contributed to study design and provided essential reagents. S.H.H prepared the inhibitor. P.S., S.P.R., R.J.W., B.D.H, and A.G.G reviewed and edited the manuscript.

Disclosures

The authors declare no conflicts of interest.
} 
These studies suggest that sEH induced by soy proteins promotes allergic responses and GI inflammation including eosinophilia and that inhibition of sEH can attenuate these responses.

\section{Keywords}

Soy proteins; eosinophilia; epithelial barrier integrity; pharmacological inhibition of soluble epoxide hydrolase

\section{Introduction}

The prevalence of food allergies is on the rise, affecting nearly 4-6\% of the population in the US [1] and impacting their daily life in various ways [2]. The term food allergy refers to an adverse immune response to food proteins which can be IgE-mediated, non-IgE-mediated, or a combination of both [3]. Acute allergic reactions triggered by IgE antibody-mediated immune responses to food proteins often involve the skin, gastrointestinal (GI) tract and respiratory tract. In contrast, non-IgE-mediated food allergy primarily affects the GI mucosa [4]. While the involvement of mast cells in food allergies is well recognized [5], increasingly, several studies have indicated a role for eosinophils in promoting food allergeninduced inflammation. Experimental animal models of food antigen-driven GI inflammation [6-8] as well as studies in patients with food allergies [9-11] show that eosinophils are recruited to the intestinal mucosa in substantial numbers. Although present in the normal GI mucosa under homeostatic conditions [12], eosinophils are known to contribute to inflammation when present in abnormal numbers [13, 14]. Studies have shown that treatment of mice with anti-siglec $\mathrm{F}$ antibody (which targets eosinophils) reduces eosinophilic inflammation in oral egg ovalbumin-induced intestinal inflammation, along with reduction of Th2 cytokines, IgE levels, intestinal permeability and weight loss[8]. In a more recent study, eosinophil-deficient mice were shown to be protected from Th-2mediated peanut food allergy [15]. Further, activated eosinophils were found to control dendritic cell activation and migration from the intestine to draining lymph nodes (necessary for Th2 priming) via release of the granule protein eosinophil peroxidase (EPX) demonstrating the ability to initiate Th-2-type immune responses. More recently, resident intestinal eosinophils have been shown to obtain access to food antigens from the lumen in an Ig-dependent manner and may participate in antigen-driven secondary immune responses to oral antigens [16]. Although the functional role of eosinophils in the pathogenesis of food allergen-induced GI inflammation is still emerging, many studies suggest a proinflammatory role for these cells in the GI tract (reviewed in [17]).

Soluble epoxide hydrolase (sEH) is the major enzyme involved in the metabolism of epoxyeicosatrienoic acids (EETs), which are lipid mediators that act as signaling molecules to regulate inflammation (anti-inflammatory), into pro-inflammatory dihydroxyeicosatrienoic acids (DiHETs) [18]. Thus, sEH has a pro-inflammatory role in various inflammation models $[19,20]$. Recently, the beneficial effect of sEH deficiency or inhibition on the outcome of GI inflammation such as pancreatitis [21] and inflammatory bowel disease (IBD) [22] was demonstrated in murine models. Additionally, in the context of eosinophil influx, inhibition of sEH resulted in reduced eosinophil recruitment and 
attenuation of allergen-induced airway inflammation in a murine model [23]. These studies suggest that blockade of sEH may help in preventing food antigen-induced eosinophilic disorders.

While various approaches to treatment of food allergies are under investigation [24], currently, avoidance of allergenic foods and prompt pharmacological treatment of acute allergic reactions are the major interventions employed in the management of food allergies [25]. Soy, which is widely used in various processed foods due to its high-quality protein content [26], is considered to be one of the more common allergenic foods [25]. Soybean allergy can range from relatively mild symptoms to severe reactions (enterocolitis, immediate IgE-mediated systemic reactions) not only in humans [27-29] but also in animal models [30-32]. In the current study, we investigated the role of sEH in a murine model of soy protein-induced food allergy and the potential use of a highly selective sEH inhibitor trans-4-\{4-[3-(4-trifluoromethoxyphenyl)-ureido]-cyclohexyloxy\}-benzoic acid ( $t$-TUCB) to attenuate soy protein-induced food allergy including eosinophil recruitment.

\section{Materials and Methods}

\section{Mouse model of soy protein-induced allergy}

BALB/c mice (Charles River Laboratories, Shrewsbury, MA) were maintained on a soy-free diet (Teklad Custom Diet [TD.95092], Envigo Bioproducts, Inc., Madison, WI) and bred inhouse. Off-spring (male and female) born to mice maintained on this soy-free diet (beyond second-generation) were fed the same soy-free diet and used in the studies. Mice (8-10 weeks) were sensitized and challenged with soy protein isolate (SPI) (kindly provided by Dr. Paraem B. Ismail, Department of Food Science and Nutrition, University of Minnesota, Saint Paul, MN 55108) [33]. The protocol for SPI challenge and treatment with $t$-TUCB, a synthetic pharmacologic inhibitor of sEH, is shown in Figure 1, A. The oral allergen challenge protocol was similar to a previous study in which peanut extract was used instead of soy [34]. $t$-TUCB was synthesized as described previously [35] and its efficacy as a potent inhibitor of sEH in vivo in mice has been previously established [23, 36]. $t$-TUCB dissolved in PEG-400 (Sigma-Aldrich Corp., St. Louis, MO) was administered orally to the mice at 1 or $3 \mathrm{mg} / \mathrm{kg}$ two hours before each challenge. $t$-TUCB administered at these doses has previously been shown to be effective in attenuating experimental allergen-induced airway inflammation in mice[23]. Control mice received saline instead of the drug. Mice were weighed before the first challenge and at the end of the study. All studies involving mice were performed following procedures and standards approved by the local Institutional Animal Care and Use Committee.

\section{Sample collection and analysis}

At the end of the study, blood, bone marrow (BM) and jejunum were collected from allergen-challenged and control mice. Blood and BM were used to determine differential cell counts from cytocentrifuged samples based on morphologic and histologic criteria after staining with the Hema 3 System (Thermo Fisher Scientific Co., Pittsburgh, PA). Serum was used to determine IgE levels. The jejunum was divided into two segments. One segment was 
perfused with saline and snap-frozen in liquid nitrogen while the other was perfused and fixed in $4 \%$ (vol/vol) paraformaldehyde for $24 \mathrm{~h}$ before paraffin embedding.

\section{Measurement of total and soy-specific $\lg \mathrm{E}$}

Total IgE in serum was measured using a mouse IgE ELISA kit (BioLegend, San Diego, CA) as per the manufacturer's recommendation. SPI-specific IgE levels were measured by an ELISA developed in-house. Briefly, SPI was dissolved in PBS at a concentration of 1 $\mathrm{mg} / \mathrm{ml}$. The suspension was vortexed and then briefly centrifuged to remove insoluble particles. The supernatant was collected and used as the stock solution for coating of ELISA plates after determination of the final protein concentration. 96-well ELISA plates were coated with SPI in carbonate buffer $(\mathrm{pH} 9.5)$ at $10 \mu \mathrm{g} / \mathrm{ml}$ and incubated overnight at $4^{\circ} \mathrm{C}$. Wells were blocked for $1 \mathrm{~h}$ with $1 \%$ BSA in $0.05 \%$ Tween 20 in PBS (wash buffer). After blocking, samples (50 $\mu \mathrm{l}$ of 1:10 diluted serum) were added to the SPI-coated plate and incubated for $90 \mathrm{~min}$. Bound IgE was detected using biotinylated rat anti-mouse IgE (BD Pharmingen, San Jose, CA, 1:200, $50 \mu \mathrm{l} /$ well). After $1 \mathrm{~h}$, avidin horse radish peroxidase (HRP) $(1: 1000,50 \mu \mathrm{l})$ was added and the plates were incubated for $30 \mathrm{~min}$. Peroxidase activity was detected with SigmaFast OPD (Sigma-Aldrich, St. Louis, MO). After 20-30 min, the reaction was terminated by adding $3 \mathrm{M} \mathrm{HCl}$ and the plates were read at $492 \mathrm{~nm}$ using a FLUOStar Optima microplate reader (BMG Labtech, Durham, NC). Plates were washed $(3 \times)$ with wash buffer between each step and all incubations after coating were carried out at room temperature.

\section{Histology}

Paraffin-embedded jejunal tissue sections ( $4 \mu \mathrm{m}$ thick) were stained with Harris Modified Hematoxylin and Shandon Instant Eosin (H\&E, Thermo Fisher Scientific Co.) to determine cellular infiltration. For all immunohistochemistry, tissue sections were subjected to antigen retrieval followed by quenching of endogenous peroxidase activity prior to staining with specific antibodies and sections were briefly counterstained $(5 \mathrm{sec})$ with hematoxylin at the end of the procedure. VECTASTAIN ABC kits containing biotinylated secondary antibodies (anti-goat or anti-rat) and avidin-biotin horseradish peroxidase complex (Vector Laboratories) were used along with the Peroxidase AEC (3-amino-9-ethylcarbazole) substrate kit (Vector Laboratories) for detection. Slides were analyzed using a Nikon Microphot EPI-FL microscope equipped with an Olympus DP71 camera for image capture. Expression of sEH in the jejunum was evaluated by immunohistology using goat polyclonal antibodies against murine sEH ( $1 \mu \mathrm{g} / \mathrm{ml}$, Santa Cruz Biotechnology, Inc., Dallas, TX). Infiltration of eosinophils in the jejunal tissue was assessed by staining for eosinophilspecific major basic protein (MBP) expression using rat mAb against murine MBP (2 $\mu \mathrm{g} / \mathrm{mL}$ ) as described in our previous studies [37]. MBP-positive cells (stained reddish brown) were found largely localized at the tip of the villi. Therefore, cells in nonoverlapping microscopic fields covering the tip of each villus in the entire section $(11 \pm 1$ fields/mouse) were counted at 400× magnification and expressed as the average number of cells per field. To assess expression of sEH by tissue eosinophils, sections were dual-stained with antibodies against sEH $(1 \mu \mathrm{g} / \mathrm{ml}$, Santa Cruz Biotechnology, Inc.) and mAb against EPX $(10 \mu \mathrm{g} / \mathrm{ml})$, an eosinophil specific marker [37], followed by FITC-conjugated donkey anti-goat IgG and Rhodamine Red X-conjugated donkey anti-mouse IgG as secondary 
antibodies. For expression of junction proteins in the jejunum, paraffin-embedded sections ( $4 \mu \mathrm{m}$ thick) were incubated with rabbit polyclonal antibodies against occludin $(0.5 \mu \mathrm{g} / \mathrm{ml}$, Abcam, Cambridge, Massachusetts) or ZO-1 ( $8 \mu \mathrm{g} / \mathrm{ml}$, Santa Cruz Biotechnology, Inc.) or rabbit $\mathrm{mAb}$ against E-cadherin $(2.5 \mu \mathrm{g} / \mathrm{ml}$, Abcam $)$ followed by FITC-conjugated donkey anti-rabbit IgG. All secondary antibodies for immunofluorescent staining (Jackson ImmunoResearch Laboratories, West Grove, PA) were used at $10 \mu \mathrm{g} / \mathrm{ml}$. Rat IgG (for MBP), goat IgG (for sEH), mouse IgG (for EPX) and rabbit IgG (for occludin, ZO-1 and Ecadherin) were used as control antibodies. Stained slides were analyzed using a Confocal Laser Scanning Biological Microscope (FLUOVIEW FV1000/BX61) equipped with UPlanSApo $(20 \times / 0.85$ [oil] $)$ and PlanApo N $(60 \times / 1.42$ [oil] $)$ lenses and FV10-ASW 3.1 software for image acquisition (Olympus, Melville, NY). Mast cells were detected based on chloroacetate esterase (CAE) staining performed as described previously [38]. Briefly, jejunal sections were stained with freshly prepared CAE solution for $45 \mathrm{~min}$ at room temperature, washed, counterstained with hematoxylin followed by a change of lithium carbonate and then mounted. Positively stained cells (dark purple) in randomly selected nonoverlapping microscopic fields ( $20 \pm 1$ fields/mouse) covering the lower lamina propria in the section were counted at $400 \times$ magnification and expressed as the average number of cells per field. Mucus accumulation in the jejunum was assessed by staining jejunal sections with periodic acid-Schiff (PAS) reagent (Sigma-Aldrich Corp.) followed by quantitation of the positive staining (dark pink) from captured images using ImageJ image analysis software [39]. PAS-positive area in all intact villi in each image was quantitated for each mouse and expressed as percent PAS-positive area/villus as outlined previously [40].

\section{Culture of BM-derived murine eosinophils}

Eosinophils were cultured from BM of naïve mice (on soy-free diet) as described previously [41, 42]. Differentiated cells were evaluated for expression of MBP by confocal microscopy using rat $\mathrm{mAb}$ against murine MBP $(2.5 \mu \mathrm{g} / \mathrm{ml})$ followed by FITC-conjugated goat anti-rat IgG and of Siglec-F by flow cytometry (FACScan and CellQuest Pro ${ }^{\mathrm{TM}}$ Software, BD Biosciences, San Diego, CA) with PE-conjugated rat anti-mouse Siglec-F (5 $\mu \mathrm{g} / \mathrm{ml}, \mathrm{BD}$ Biosciences). Cells between days 12-14 of culture that were 99\% Hema 3-positive and expressed both MBP and Siglec-F were used in studies.

To examine the effect of $t$-TUCB on signaling events, eosinophils on day 12 of culture were harvested and treated with $t$-TUCB $(5 \mu \mathrm{M})$ or DMSO (vehicle control) in PBS for 1,10 or $30 \mathrm{~min}$ at $37^{\circ} \mathrm{C}$ and processed for Western blot analysis (described below). The effect of inflammatory mediators on expression of sEH was examined by culturing cells $\left(\sim 5 \times 10^{6} \%\right.$ well) in medium containing $10 \%$ FBS and IL-4, TNFa (at $100 \mathrm{ng} / \mathrm{ml}$ ) or eotaxin-1 (at 100 $\mathrm{nM}$, all from PeproTech, Rocky Hill, NJ) for $24 \mathrm{~h}$ at $37^{\circ} \mathrm{C}$ and then evaluating sEH by Western blot analysis.

\section{Western blot analysis}

Jejunal tissue and BM eosinophils were lysed in RIPA buffer containing phosphatase inhibitor cocktail A and B (Santa Cruz Biotechnology, Inc.) and protease inhibitor cocktail (Sigma-Aldrich Corp.). Total protein in the supernatants was measured using the BCA Protein Assay Kit (Pierce, Rockford, IL). Lysates were electrophoresed on 10 (for sEH, 40 
$\mu \mathrm{g} / \mathrm{lane}$ for eosinophil lysates and $10 \mu \mathrm{g} / \mathrm{lane}$ for tissue lysates) or 12 (for ERK (1/2), 20 $\mu \mathrm{g} / \mathrm{lane}) \%$ SDS polyacrylamide gels under reducing conditions and transferred to PVDF membranes $(0.2 \mu \mathrm{M}$, Millipore, Billerica, MA). sEH in lysates of the jejunum was detected using rabbit anti-mouse sEH generated as described previously [43], while sEH in eosinophil lysates was detected with a goat polyclonal antibody against murine sEH $(0.4$ $\mu \mathrm{g} / \mathrm{ml}$, Santa Cruz Biotechnology, Inc.) in the presence or absence of a sEH antibody blocking peptide ( $5 \times$ concentration of primary antibody, Santa Cruz Biotechnology, Inc.) followed by HRP-conjugated anti-rabbit $(0.2 \mu \mathrm{g} / \mathrm{ml}$, Jackson ImmunoResearch Laboratories) or anti-goat antibody ( $0.2 \mu \mathrm{g} / \mathrm{ml}$, Santa Cruz Biotechnology, Inc.). Expression level of $\beta$ actin was monitored as an internal control using HRP-conjugated mouse mAb against actin $(0.06 \mu \mathrm{g} / \mathrm{ml}$, Santa Cruz Biotechnology, Inc.). ERK (1/2) activation was assessed using phopho-p44/42 MAPK (phospho-ERK (1/2), T202/Y204) rabbit polyclonal antibodies $(0.048 \mu \mathrm{g} / \mathrm{ml})$ and $\mathrm{p} 44 / 42 \mathrm{MAPK}$ rabbit mAb (ERK (1/2), $0.027 \mu \mathrm{g} / \mathrm{ml}$, both from Cell Signaling Technology, Inc., Danvers, MA. Bound antibodies were detected using peroxidase-conjugated AffiniPure goat anti-mouse $\operatorname{IgG}(\mathrm{H}+\mathrm{L})$ or goat anti-rabbit $\operatorname{IgG}(\mathrm{H}+\mathrm{L})$ $(0.26 \mu \mathrm{g} / \mathrm{ml}$, Jackson ImmunoResearch Laboratories). Protein bands were detected using Western Bright ${ }^{\mathrm{TM}}$ ECL (Advansta, Menlo Park, CA) and visualized on X-ray films. Intensity of detected bands for ERK (1/2) was quantified using ImageJ image analysis software and expression level of phospho-ERK (1/2) was normalized against that of total ERK (1/2).

\section{Immunofluorescence staining}

For expression of sEH by BM eosinophils, cells were cytocentrifuged on to glass slides, fixed with $4 \%$ paraformaldehyde (20 min) and permeabilized with $0.2 \%$ Triton X-100 (10 min). After blocking (1.5\% goat serum in TBS, blocking buffer), cells were incubated overnight at $4{ }^{\circ} \mathrm{C}$ with polyclonal antibodies against mouse sEH $(1 \mu \mathrm{g} / \mathrm{ml}$, Santa Cruz Biotechnology, Inc.) in the absence and presence of sEH antibody blocking peptide (5x concentration of antibody, Santa Cruz Biotechnology, Inc.) or with goat IgG (control) in blocking buffer. Bound antibodies were detected using Rhodamine Red-X-conjugated antigoat IgG (10 $\mu \mathrm{g} / \mathrm{ml}$, Jackson ImmunoResearch Laboratories, Inc.). Cells were counterstained with DAPI to visualize nuclei and examined using a confocal microscope.

\section{Adhesion and migration assays}

Effect of $t$-TUCB on eosinophil adhesion and migration was determined as described previously [37]. Briefly, cells treated with $t$-TUCB (5 or $10 \mu \mathrm{M}, 30 \mathrm{~min}$ at $37^{\circ} \mathrm{C}$ ) or DMSO were placed on recombinant mouse vascular cell adhesion molecule-1 (rmVCAM-1)-coated cover-slips $\left(5 \times 10^{5}\right.$ cells/cover-slip) for $30 \mathrm{~min}$. After washing, adherent cells were fixed and permeabilized with $4 \%$ paraformaldehyde and $0.1 \%$ saponin in PBS and stained with Alexa Fluor 488 Phalloidin (1:200, Thermo Fisher Scientific Co.) followed by DAPI to visualize nuclei. The number of adherent cells in five randomly selected fields of each coverslip was counted under a confocal microscope ( $\times 200$ magnification). To examine the effect of $t$-TUCB on eosinophil migration, cells treated with $t$-TUCB $\left(1-10 \mu \mathrm{M}, 30 \mathrm{~min}\right.$ at $\left.37^{\circ} \mathrm{C}\right)$ or DMSO were added to the upper wells of Transwell ${ }^{\circledR}$ 96-well plates (Corning Life Sciences, Tewksbury, MA) and migration towards murine eotaxin-1 (CCL11, 100nM, PeproTech) in the lower wells of the chambers was assessed after $3-4 \mathrm{~h}$ at $37^{\circ} \mathrm{C}$. The number of migrating cells was evaluated using an Olympus CK2 inverted microscope $(\times 200$ 
magnification). Cells in ten randomly selected non-overlapping fields were counted for each well and expressed as percent migration relative to vehicle-treated cells. In some experiments, cells were treated with 11,12-EET or 11,12-DiHET (both from Cayman Chemical Company, Ann Arbor, MI) at 1, 5 or $10 \mu \mathrm{M}$ or EtOH (vehicle control) for $30 \mathrm{~min}$ at $37^{\circ} \mathrm{C}$ and examined for their ability to migrate as described above.

\section{Cell surface receptor expression}

Eosinophils were treated with $t$-TUCB $(10 \mu \mathrm{M})$ or DMSO in PBS for $30 \mathrm{~min}$ at $37^{\circ} \mathrm{C}$ and then examined by flow cytometry for changes in expression of cell surface adhesion molecules using mAb against CD49d ( $a$ 4, Clone PS/2), CD11a ( $a$ L, eBioscience, San Diego, CA), CD11b (aM, eBioscience), L-selectin (Clone MEL-14) or CD18 ( $\beta 2$, Clone 2E6) followed by FITC-conjugated goat anti-rat IgG (Jackson ImmunoResearch Laboratories, Inc.) or FITC-conjugated goat anti-hamster IgG (BioLegend, San Diego, CA, for CD18). Rat IgG2b (eBioscience, for CD49d and CD11b), rat IgG2a (eBioscience, for CD11a and L-selectin) or hamster IgG (BioLegend, for CD18) were used as isotype controls. All antibodies were used at $10 \mu \mathrm{g} / \mathrm{ml}$.

\section{C-C chemokine receptor type 3 (CCR3) expression and actin polymerization}

Eosinophils were treated with $t$-TUCB $(5 \mu \mathrm{M})$ as described earlier and examined by flow cytometry for changes in cell surface expression of CCR3, the receptor for eotaxin-1, with FITC-conjugated rat anti-mouse CCR3 $(2.5 \mu \mathrm{g} / \mathrm{ml}, \mathrm{R} \& D$ Systems, Minneapolis, MN). FITC-conjugated rat IgG2a was used as the isotype control. For detection of actin polymerization, $t$-TUCB-treated cells were fixed and permeabilized using $4 \%$ paraformaldehyde and $0.1 \%$ saponin in PBS for 20 min on ice. Cellular F-actin was stained with Alexa Fluor 488 Phalloidin (Thermo Fisher Scientific Co.) and analyzed by flow cytometry.

\section{Intracellular $\mathrm{Ca}^{2+}$ imaging}

Basal and agonist-induced changes in intracellular $\mathrm{Ca}^{2+}\left(\left[\mathrm{Ca}^{2+}\right]_{\mathrm{i}}\right)$ levels in eosinophils were determined using the cell permeant $\mathrm{Ca}^{2+}$ indicator dye Fura-2AM (Thermo Fisher Scientific Co.) as described previously [41]. Briefly, eosinophils attached to poly-L-lysine-coated (10 $\mu \mathrm{g} / \mathrm{ml}$ ) glass cover-slips were loaded with $5 \mu \mathrm{M}$ Fura-2 AM in HBSS for $30 \mathrm{~min}$ at $37^{\circ} \mathrm{C}$ and 5\% CO2. Cover-slips were washed gently with HBSS containing $10 \mathrm{mM}$ HEPES, $11 \mathrm{mM}$ glucose, $2.5 \mathrm{mM} \mathrm{CaCl}_{2}$, and $1.2 \mathrm{mM} \mathrm{MgCl}_{2}(\mathrm{pH} \mathrm{7.4)}$ and mounted on the stage of a Nikon Diaphot inverted microscope in an open slide chamber. Fura-2 AM-loaded cells were alternately excited at 340 and $380 \mathrm{~nm}$ with a Lambda DG-4 high-speed wavelength switcher (Sutter Instrument Co., Novato, CA). $\left[\mathrm{Ca}^{2+}\right]_{\mathrm{i}}$ was measured by real-time digital video fluorescence imaging using NIS-Elements imaging software (Nikon Instruments Inc., Melville, NY). After measuring basal $\left[\mathrm{Ca}^{2+}\right]_{\mathrm{i}}$ for 2 min, $t$-TUCB $(5 \mu \mathrm{M})$ or DMSO was added and cells were evaluated for $4 \mathrm{~min}$. Eosinophils were then stimulated with eotaxin-1 (Peprotech) to assess agonist-induced $\left[\mathrm{Ca}^{2+}\right]_{\mathrm{i}}$ responses or to $2 \mu \mathrm{M}$ ionomycin, free acid (Biovision, Milpitas, CA) as a positive control and evaluated for an additional $3 \mathrm{~min}$. The ratio of fluorescence emissions at $340 \mathrm{~nm}$ and $380 \mathrm{~nm}$ was determined at each time point which is directly reflective of the amount of $\left[\mathrm{Ca}^{2+}\right]_{\mathrm{i}}$. 


\section{Statistical analysis}

Combined data (mean \pm SEM) of three separate experiments for in vivo studies and of experiments performed at least three times in duplicate or triplicate for in vitro studies is shown. Statistical significance between two groups was determined using a two-tail unpaired Student's $t$-test. Comparisons between multiple treatments were carried out by One-way ANOVA using Tukey-HSD post-hoc test. A $p$ value $<0.05$ was considered to be significant.

\section{Results}

\section{Exposure of mice on a soy-free diet to SPI leads to increased expression of intestinal sEH}

Since the goal of the current study was to examine the potential pro-inflammatory role of sEH in food allergen-induced GI inflammation, we used a mouse model of soy proteininduced GI inflammation. Mice maintained on a soy-free diet were exposed to SPI, as outlined in Fig. 1A. SPI-challenged mice demonstrated increased expression of sEH in the epithelium of the villi as well as in the crypts of the lamina propria in the jejunum based on immunohistology (Fig. 1, B) and Western blot analysis of tissue lysate (Fig. 1, C).

Consistent with the development of an allergic response, SPI-challenged mice demonstrated elevated total and antigen-specific IgE levels in the serum relative to control mice (Fig. 2, A and B, respectively) and mild cellular inflammation in the intestine based on histological examination after H\&E staining (data not shown). Additionally, SPI-exposed mice exhibited marked weight loss relative to control mice by the end of the study (Fig. 2, C) but did not develop diarrhea or other symptoms such as skin lesions, changes in fur characteristics or behavior. In order to establish whether increased expression of sEH in the GI tract of SPIchallenged mice plays a role in promoting allergic responses and inflammation, mice exposed to SPI were administered orally with $t$-TUCB (as outlined in Fig. 1, A), a highly selective pharmacological inhibitor of sEH previously shown to attenuate inflammation in other experimental models [23, 44]. Administration of $t$-TUCB significantly inhibited total and antigen-specific IgE levels (Fig. 2, A and B, respectively) and prevented SPI-induced weight loss in a dose-dependent manner.

\section{SPI challenge leads to recruitment of eosinophils and mast cells which is inhibited by t- TUCB}

Although eosinophils are present in the normal GI tract [12], food antigen-driven inflammation is known to be associated with increased presence of eosinophils in the GI tract [11]. SPI challenge resulted in a marked increase in the number of eosinophils in the jejunum compared to control mice based on immunostaining for MBP, an eosinophilspecific granule protein. Eosinophils were largely localized at the tip of the villi, with fewer cells detected in the lower lamina propria. Eosinophil recruitment was significantly reduced in SPI-challenged mice treated with $t$-TUCB at $1 \mathrm{mg} / \mathrm{kg}$ or $3 \mathrm{mg} / \mathrm{kg}$ (Fig. 3, A and B). Dualimmunostaining studies showed that eosinophils in the villi of SPI-challenged mice express sEH based on positive staining for EPX (eosinophil-specific marker) and sEH (Fig. 3, C). This is the first evidence that eosinophils express sEH. Because of the increased presence of eosinophils in the jejunum of SPI-challenged mice, we determined eotaxin levels in jejunal tissue lysates (Fig. 3, D). SPI-challenged mice had higher levels of eotaxin-1 compared to control mice which was not affected by treatment with $t$-TUCB, suggesting that the reduced 
recruitment of eosinophils noted in the $t$-TUCB-treated mice is not likely to be linked to eotaxin-1 levels. SPI challenge had no effect on eotaxin-2 levels. In addition to eosinophils, the presence of mast cells in the jejunum of SPI-challenged mice was evaluated based on CAE staining. Quantitation of stained jejunal sections indicated an increased number of CAE-positive cells in SPI-challenged mice relative to control mice notably in the lower lamina propria but not in the villi. As noted in the case of eosinophils, administration of $t$ TUCB to SPI-challenged mice significantly decreased the number of CAE-positive cells in the jejunum relative to untreated mice (Fig. 3, E and F).

\section{t-TUCB reduces SPI-induced mucus secretion and loss of epithelial junction proteins in the GI tract}

Mucus hypersecretion is a characteristic feature of airway [45] and oral allergen exposure [46]. Consistent with this, a two-fold increase in mucus secretion by goblet cells in the epithelium of the villi was noted in SPI-challenged mice compared to control mice based on staining with PAS (Fig. 4, A). Treatment with $t$-TUCB significantly inhibited mucus secretion with levels similar to that noted in control mice (Fig. 4, A and B). Barrier function of the intestinal epithelium, which is tightly regulated by epithelial junction proteins, plays a crucial role in preventing passage of harmful agents, including dietary antigens, from the lumen of the gut into the mucosal tissues and circulatory system [47]. We examined expression of epithelial occludin, ZO-1 and E-cadherin in our model of SPI-induced GI allergy by immunofluorescence staining of jejunal sections (Fig. 4, C-E). Consistent with the phenotype associated with GI inflammation, SPI challenge resulted in a marked reduction in expression of epithelial occludin, ZO-1 and E-cadherin relative to control mice (Fig. 4, C and D, middle and top panels, respectively, Fig. 4, E, middle and left panels, respectively). In SPI-challenged mice treated with $t$-TUCB at $3 \mathrm{mg} / \mathrm{kg}$, loss of occludin and E-cadherin expression was substantially prevented (Fig. 4, C, bottom panels, and E, right panels), while recovery of ZO-1 expression was less striking (Fig. 4, D, bottom panels). Overall, these studies suggest that sEH induced by food allergens such as soy proteins promotes GI allergic responses and inflammation and that inhibition of sEH can attenuate SPI-induced allergic responses.

\section{Expression and induction of sEH in murine eosinophils}

As indicated earlier, eosinophils recruited to the GI tract of SPI-challenged mice express sEH (Fig. 3, C). Since $t$-TUCB treatment reduced eosinophil recruitment to the jejunum in SPI-challenged mice (Fig. 3, A and B) but did not alter levels of the eosinophil chemokine eotaxin-1 (Fig. 3, D), we investigated whether the reduced eosinophil recruitment could be due to a direct effect of the inhibitor on eosinophil-expressed sEH. We first examined expression of sEH and its regulation using BM-derived murine eosinophils. Immunofluorescence staining of eosinophils with polyclonal antibodies against murine $\mathrm{sEH}$ demonstrated positive staining largely localized in the cytoplasm (Fig. 5, A). Western blots of eosinophil lysates indicated a band of $\sim 64 \mathrm{kDa}$ (Fig. 5, B) corresponding to the known molecular weight of sEH [48]. In the immunofluorescence staining studies and Western blots, incubation with the primary antibody in the presence of a sEH antibody blocking peptide markedly decreased intensity of sEH expression, indicating the specificity of the staining detected (Fig. 5, A, bottom panels and B, right panels). Next, we examined whether 
pro-inflammatory cytokines likely to be associated with allergic responses in the GI tract such as IL-4, TNF- $a$ and eotaxin-1 regulate expression of sEH in eosinophils. BM eosinophils treated with IL-4, TNF-a or eotaxin- 1 for $24 \mathrm{~h}$ were analyzed for expression of sEH by Western blot analysis. TNF-a was found to significantly induce expression of sEH, while IL-4 had no effect and a marginal increase in expression of sEH was noted with eotaxin-1 (Fig. 5, C).

\section{t-TUCB inhibits eosinophil adhesion and migration}

We next examined whether $t$-TUCB has a direct effect on adhesive events associated with eosinophil recruitment such as adhesion to endothelial adhesion molecules and migration. Treatment of eosinophils with $t$-TUCB at a concentration of $10 \mu \mathrm{M}$ significantly inhibited adhesion to VCAM-1 compared to vehicle-treated cells (Fig. 6, A) but did not alter expression levels of CD49d, CD18, CD11a, CD11b or L-selectin (Fig. 6, B). Treatment of eosinophils with $t$-TUCB also reduced eotaxin-1-induced migration relative to vehicletreated cells, with significant inhibition noted at a concentration of $5 \mu \mathrm{M}$ (Fig. 6, C). Interestingly, $t$-TUCB at this concentration had no effect on expression levels of the eotaxin-1 receptor CCR3 on eosinophils (Fig. 6, D). Studies have shown that $t$-TUCB inhibits the ability of sEH to convert EETs into DiHETs [19]. While EETs exert various anti-inflammatory effects, DiHETs are pro-inflammatory [19]. We therefore examined the effect of increasing concentrations of a representative EET and DiHET on eosinophil migration. Consistent with our finding that $t$-TUCB treatment inhibits migration, treatment of eosinophils with increasing concentrations of 11,12-EET inhibited eosinophil migration while 11,12-DiHET had no effect (Fig. 6, E).

\section{Effect of t-TUCB on intracellular signaling events}

Since pre-treatment of eosinophils with $t$-TUCB altered the ability of cells to adhere to and migrate but did not affect expression of adhesion molecules or CCR3, we examined its effect on intracellular signaling events that regulate cell motility. The effect of $t$-TUCB on the actin cytoskeleton was evaluated by flow cytometry. Treatment with $t$-TUCB $(5 \mu \mathrm{M})$ up to $20 \mathrm{~min}$ did not alter phalloidin binding (indicative of actin polymerization) relative to vehicletreated cells (Fig. 7, A), suggesting that the actin cytoskeleton may not be a target of $t$ TUCB. On the other hand, $t$-TUCB treatment altered ERK (1/2) activation in eosinophils. Western blots analysis followed by densitometry for levels of phospho-ERK (1/2) in cells treated with $t$-TUCB or the vehicle control (DMSO) up to $30 \mathrm{~min}$ (duration of pre-treatment in migration assays) revealed that vehicle-treated cells exhibit increased ERK (1/2) activation at $30 \mathrm{~min}$ relative to earlier time points $(1$ and $10 \mathrm{~min})$ whereas $t$-TUCB-treated cells showed decreased ERK (1/2) activation at this time point with levels of phospho-ERK (1/2) being significantly lower compared to vehicle-treated cells (Fig. 7, B). In addition, $\left[\mathrm{Ca}^{2+}\right]_{\mathrm{i}}$ was altered by $t$-TUCB. $t$-TUCB induced an increase in $\left[\mathrm{Ca}^{2+}\right]_{\mathrm{i}}$ relative to vehicletreated cells. Levels remained elevated up to $6 \mathrm{~min}$ and then gradually decreased but failed to increase upon exposure to eotaxin-1. On the other hand, vehicle-treated cells demonstrated a clear eotaxin-1-induced surge in $\left[\mathrm{Ca}^{2+}\right]_{\mathrm{i}}$ (Fig. 7, C, upper panel). Both $t$ TUCB- and vehicle-treated cells responded comparably to ionomycin, a $\mathrm{Ca}^{2+}$ ionophore that directly transports $\mathrm{Ca}^{2+}$ across biological membranes to artificially increase $\left[\mathrm{Ca}^{2+}\right]_{\mathrm{i}}$ (Fig. 7 , 
$\mathrm{C}$, lower panel), suggesting that eotaxin-1-induced $\left[\mathrm{Ca}^{2+}\right]_{\mathrm{i}}$ response is altered in $t$-TUCBtreated cells.

\section{Discussion}

The epithelial surface of the GI tract not only plays a critical role in efficient uptake of nutrients and water but also functions as a barrier by limiting entry of various harmful agents present in the lumen such as bacterial pathogens, undigested food proteins and dietary allergens. For the most part, there is sufficient interaction between luminal antigens/ allergens and the mucosal immune system resulting in the development of tolerance and homeostasis in the GI tract [49]. However, a breach in the barrier functions of the sensitized GI tract can lead to increased intestinal permeability to allergens resulting in the development of food allergies [50, 51]. Food antigens/allergens can cause inflammatory disorders such as eosinophilic esophagitis, eosinophilic gastroenteritis and eosinophilic colitis $[10,11,25]$. Previous studies have indicated a role for sEH in models of GI inflammation such as IBD, colitis and acute pancreatitis [21, 22, 52]. In these studies, increased expression of sEH was noted in the inflamed tissue and genetic deletion or pharmacological inhibition of sEH resulted in amelioration of inflammation including the infiltration of inflammatory cells. However, the role of sEH in food antigen-driven GI inflammation has not been investigated.

Soybean proteins are known to induce allergic reactions (colitis) in the GI tract of humans [28] and animals [30-32]. In the current study, we investigated the role of sEH in an experimental model of soy protein-induced GI inflammation. Increased expression of sEH was noted in the epithelium of the villi and the crypts of the jejunum of soy-free mice that were fed SPI. Additionally, these mice had elevated total and antigen-specific IgE levels along with weight loss relative to control mice indicating the development of an allergic response to the food antigen. Interestingly, in SPI-challenged mice that were administered with $t$-TUCB, an inhibitor of sEH, food antigen-induced weight loss was prevented and total as well as antigen-specific IgE levels were significantly lower, specifically at the higher dose administered $(3 \mathrm{mg} / \mathrm{kg})$, indicating that specific inhibition of $\mathrm{sEH}$ attenuates these allergic responses. As indicated earlier, $\mathrm{sEH}$ is the major enzyme involved in the metabolism of EETs, thus modulating endogenous levels of these anti-inflammatory lipid mediators [19]. It is well established that sEH inhibition leads to increase in epoxide:diol ratio, which is associated with resolution of inflammation and tissue repair [43, 53]. EETs, specifically 8,9EET, can inhibit B cell function including antibody production [54]. Inhibition of sEH in $t$ TUCB-treated mice leading to increased levels of EETs and other epoxide fatty acids may be responsible for the reduced total and antigen-specific IgE levels noted in these mice.

Despite the lack of exaggerated inflammation in the jejunum based on H\&E staining, a significant increase was noted in the number of eosinophils present in the jejunum of SPIchallenged mice relative to control mice. Eosinophils are known to be present in the lamina propria of the GI tract under homeostatic conditions where they participate in biological processes such as immunoregulation, maintenance of glucose homeostasis, protection against obesity, etc., [12]. However, there is strong evidence that increased presence of eosinophils in the intestinal tract contributes to GI disorders $[13,14,55]$. Because of their 
ability to release cytotoxic granule proteins, lipid mediators, cytokines and chemokines, eosinophils in the GI tract have been shown to promote pro-inflammatory effects in clinical and experimental models [56] including compromising epithelial barrier function [57]. In our studies, SPI-challenged mice treated with the sEH inhibitor had significantly fewer eosinophils in the jejunum. Since eotaxin-1 is a major eosinophil chemoattractant that is constitutively expressed in the GI tract [58] and plays a critical role in eosinophilic GI inflammation [6], we measured levels of this chemokine in the jejunum. Interestingly, the reduction in eosinophils noted in SPI-challenged mice treated with $t$-TUCB did not correlate with eotaxin-1 levels, suggesting that this reduction might be due to a direct effect of the inhibitor on eosinophils. While macrophages, neutrophils and endothelial cells have been shown to express sEH [18], its expression in eosinophils has not been previously described. Our studies show that eosinophils in the villi of SPI-challenged mice and BM-derived murine eosinophils express sEH which could be targeted by $t$-TUCB.

In addition to eosinophils, SPI-challenged mice had increased mast cells relative to control mice. This finding was consistent with previous studies where an increased number of mast cells were detected in the small intestine in mice sensitized and challenged with soy bean proteins [30]. The involvement of mast cells in food allergies is well recognized [5]. During food allergy, mast cells undergo degranulation in the intestinal mucosa as shown in humans upon allergen provocation [59] as well as in mice [30]. Activated mast cells contribute to the pathophysiology of food allergy by releasing various pro-inflammatory mediators (histamine, serine proteases [tryptase, chymase], lipid mediators, cytokines, chemokines, etc.) that can promote ongoing inflammation in various ways including impairment of intestinal barrier function [5, 60, 61]. As noted in the case of eosinophils, SPI-challenged mice treated with $t$-TUCB had significantly fewer mast cells in the jejunum, thus limiting the ability of these cells to promote inflammation. Since the focus of the current study was to investigate the role of sEH in food allergy and specifically in allergen-induced eosinophilic inflammation in the GI tract, the effect of $t$-TUCB on mast cells at a cellular level in vitro was not investigated. Nonetheless, treatment with $t$-TUCB clearly appears to inhibit mast cell recruitment to the GI tract in SPI-challenged mice. Interestingly, decreased mast cell recruitment in vivo by pharmacological inhibition of sEH was noted in a rat model of diet-induced metabolic syndrome [62].

The GI epithelium is lined by a layer of mucus which acts as a protective barrier from harmful substances, lubricates the cell surface, regulates ion fluxes and participates in innate and adaptive immune responses [63]. Thus, altered mucus secretion (increased levels/ chemical composition) could contribute to pathological conditions such as chronic inflammation. Immune cells such as eosinophils and mast cells recruited to sites of inflammation as noted in the current study are known to release mediators upon activation (i.e., eosinophil cationic protein, cytokines, lipid mediators, histamine, tryptases, chymase) that induce mucus secretion $[56,60]$. While there are no studies with soy peptides, peptides from other foods such as whey, casein and gluten have been shown to stimulate mucin secretion in intestinal cells $[64,65]$. In the current study, mice challenged with SPI exhibited increased mucus secretion particularly in the villi and treatment with $t$-TUCB completely inhibited this allergen-induced response correlating with decreased numbers of eosinophils and mast cells in the jejunum of these mice. In addition to the mucus layer, tight junction 
proteins play an important role in the maintenance and regulation of epithelial barrier function [47]. Altered expression of tight junction proteins is considered to be a contributing factor to GI inflammation in food allergies [49, 50, 66]. Mediators released by activated eosinophils and mast cells such as granule proteins [57, 67], inflammatory cytokines (e.g., $\mathrm{TNFa}$ ), tryptases, etc., as well as Th2 cytokines have been shown to alter expression of tight junction proteins and impair barrier integrity $[49,50,66]$. In addition, there is evidence that food allergens can decrease expression of occluding, claudin-1 and ZO-1 in small intestinal biopsies from patients with food allergy (i.e., sensitized individuals) but not normal subjects [68]. Our study indicated that SPI challenge of sensitized mice not only decreased expression of occludin and ZO-1 but also of the adherens junction protein E-cadherin in the epithelium of the jejunum. Treatment of SPI-challenged mice with $t$-TUCB prevented the allergen-induced loss of these junction proteins to variable levels. In this context, previous studies have shown that diols of linoleate epoxides increase intercellular junction permeability of rat alveolar epithelial monolayers suggesting loss of epithelial integrity [69]. Based on the observation of increased IgE levels and mast cells as well as several other aspects of GI inflammation (eosinophilia, increased mucus secretion, disruption of junction protein expression) noted in our studies, it is likely that SPI-induced GI inflammation is driven by a combination of IgE-mediated and non-IgE-mediated effects. More importantly, inhibition of sEH resulted in marked attenuation of these SPI-induced allergic responses in vivo.

At a cellular level, we found that TNF-a and eotaxin-1, both of which are associated with allergic responses in the GI tract (i.e., increased presence of mast cells and eosinophils), induce expression of sEH by eosinophils. Since $t$-TUCB treatment reduced eosinophil recruitment to the jejunum in SPI-challenged mice but did not affect eotaxin-1 levels, we examined whether the inhibition of eosinophil-expressed sEH might directly affect cell adhesion and migration which are key events during cell trafficking to sites of inflammation. Indeed $t$-TUCB-treated eosinophils adhered in significantly fewer numbers to the endothelial cell adhesion molecule VCAM-1 and showed decreased migration towards eotaxin-1. As stated earlier, sEH hydrolyzes EETs that have anti-inflammatory effects into diols that can exert pro-inflammatory effects. Thus, inhibition of sEH leads to increased levels of EETs. Previous studies have shown that $t$-TUCB exerts anti-inflammatory effects on human monocytes by inhibiting lipopolysaccharide (LPS)-induced release of monocyte chemotactic protein-1 and TNF- $\alpha$ and increasing the EET to DiHET ratio (intracellular plus extracellular) [70]. 11,12-EETs have been shown to inhibit PDGF- and TGF- $\beta 1$-induced migration of smooth muscle cells in the context of mitigating pulmonary vascular remodeling [71, 72]. In addition, pharmacological inhibition of sEH has been shown to block migration of human monocytes in response to MCP-1 in vitro (which was restored in the presence of DiHETs) and in vivo in experimental models of inflammation [73]. Most importantly, consistent with our finding of decreased eosinophil migration by inhibiting sEH, treatment of eosinophils with 11,12-EET significantly inhibited eotaxin-1-induced migration in a concentration-dependent manner, while treatment with 11,12-DiHET had no effect.

Decreased adhesion and migration by inhibiting eosinophil sEH with $t$-TUCB did not appear to be due to changes in expression of cell surface adhesion molecules or the eotaxin-1 
receptor CCR3 (i.e., down-regulation), but rather due to changes in signaling events that drive cell migration. Activation of ERK (1/2) is an important signaling event elicited in eotaxin-1-exposed eosinophils and is required for cell migration in vitro $[74,75]$ and recruitment in vivo [76]. Treatment of eosinophils with $t$-TUCB strongly inhibited activation of ERK (1/2) by 30 minutes, the duration for which cells were exposed to the inhibitor before eotaxin-1 in the migration assay. This observation is consistent with the ability of 11,12-EET to inhibit eotaxin-1-induced migration. Previous studies in macrophages have shown that the MAPK pathway is a target of this sEH inhibitor; LPS-induced phosphorylation of JNK was completely abrogated when macrophages were pre-treated with $t$-TUCB [70]. Another important aspect of cell migration is $\mathrm{Ca}^{2+}$ signaling. Eotaxin-1 is known to increase $\left[\mathrm{Ca}^{2+}\right]_{\mathrm{i}}$ in eosinophils $[77,78] . \mathrm{Ca}^{2+}$ pulses near the leading edge of cells are essential for effective cell migration [79]. Consistent with previous reports where EETs have been shown to increase $\left[\mathrm{Ca}^{2+}\right]_{\mathrm{i}}$ in other cell types $[80,81]$, eosinophils treated with $t$ TUCB exhibited an increase in $\left[\mathrm{Ca}^{2+}\right]_{\mathrm{i}}$ compared to vehicle-treated cells but unlike vehicletreated cells failed to demonstrate an increase in $\left[\mathrm{Ca}^{2+}\right]_{i}$ when subsequently exposed to eotaxin-1. Thus, exposure of eosinophils to a sEH inhibitor is likely to target intracellular signaling events to inhibit cell adhesion and migration.

In summary, this study reports that expression of sEH in the GI tract is induced by food antigens such as SPI and pharmacological inhibition of sEH attenuates food antigen-induced inflammation by inhibiting recruitment of eosinophils and mast cells to the GI tract as well as preserving epithelial barrier function by inhibiting mucus hypersecretion and allergeninduced loss of junction protein expression. At a cellular level, expression of sEH in eosinophils is induced by inflammatory mediators such as TNF-a and eotaxin-1 and inhibition of sEH impedes eosinophil adhesion and eotaxin-1-induced migration by targeting ERK (1/2) activation and altering $\left[\mathrm{Ca}^{2+}\right]_{i}$ levels. Inhibition of sEH might serve as a strategy in the management of food allergies.

\section{Acknowledgments}

Support was provided in part by National Institute of Environmental Health Sciences (Award Number R01ES002710) and National Institute of Diabetes and Digestive and Kidney Diseases (Award Numbers R01DK103616 and R01DK107767) to B.D.H. and by the University of Minnesota College of Veterinary Medicine Research Office, Minnesota Agricultural Experiment Station, and General Ag Research Funds (Grant No. MIN-62-059) to R.J.W. We thank Dr. Mathur S. Kannan, Veterinary and Biomedical Sciences, University of Minnesota, for use of the equipment and helpful suggestions with regard to the intracellular calcium imaging studies.

\section{Abbreviations}

$\begin{array}{ll}\text { BM } & \text { Bone marrow } \\ \text { CCR3 } & \text { C-C chemokine receptor type 3 } \\ \text { CAE } & \text { Chloroacetate esterase } \\ \text { DiHETs } & \text { Dihydroxyeicosatrienoic acids } \\ \text { EPX } & \text { Eosinophil peroxidase }\end{array}$




\begin{tabular}{ll} 
EETs & Epoxyeicosatrienoic acids \\
FBS & Fetal bovine serum \\
GI & Gastrointestinal \\
HBSS & Hank's Balanced Salt Solution \\
HRP & Horse radish peroxidase \\
HEPES & (4-(2-hydroxyethyl)-1-piperazineethanesulfonic acid) \\
IBD & Inflammatory bowel disease \\
[Ca $\left.{ }^{2+}\right]_{\mathbf{i}}$ & Intracellular Ca ${ }^{2+}$ \\
LPS & Lipopolysaccharide \\
MBP & Major basic protein \\
mAb & Monoclonal antibody \\
PAS & Periodic acid-Schiff \\
SEH & Soluble epoxide hydrolase \\
SPI & Soy protein isolate \\
TBS & Tris-buffered saline \\
$\boldsymbol{t}$-TUCB & trans-4- $\{4$-[3-(4-trifluoromethoxyphenyl)-ureido]-cyclohexyloxy $\}$-benzoic \\
& acid \\
\hline
\end{tabular}

VCAM-1 Vascular cell adhesion molecule-1

\section{References}

1. Sicherer SH, Sampson HA. Food allergy: Epidemiology, pathogenesis, diagnosis, and treatment. J Allergy Clin Immunol. 2014; 133:291-307. [PubMed: 24388012]

2. Antolin-Amerigo D, Manso L, Caminati M, de la Hoz Caballer B, Cerecedo I, Muriel A, RodriguezRodriguez M, Barbarroja-Escudero J, Sanchez-Gonzalez MJ, Huertas-Barbudo B, Alvarez-Mon M. Quality of life in patients with food allergy. Clin Mol Allergy. 2016; 14:4. [PubMed: 26893591]

3. Waserman S, Watson W. Food allergy. Allergy Asthma Clin Immunol. 2011; 7:S7. [PubMed: 22166142]

4. Jyonouchi H. Non-IgE mediated food allergy - update of recent progress in mucosal immunity. Inflamm Allergy Drug Targets. 2012; 11:382-396. [PubMed: 22680623]

5. Kraneveld AD, Sagar S, Garssen J, Folkerts G. The two faces of mast cells in food allergy and allergic asthma: The possible concept of Yin Yang. Biochim Biophys Acta. 2012; 1822:93-99. [PubMed: 21757003]

6. Hogan SP, Mishra A, Brandt EB, Royalty MP, Pope SM, Zimmermann N, Foster PS, Rothenberg ME. A pathological function for eotaxin and eosinophils in eosinophilic gastrointestinal inflammation. Nat Immunol. 2001; 2:353-360. [PubMed: 11276207]

7. Cardoso CR, Teixeira G, Provinciatto PR, Godoi DF, Ferreira BR, Milanezi CM, Ferraz DB, Rossi MA, Cunha FQ, Silva JS. Modulation of mucosal immunity in a murine model of food-induced intestinal inflammation. Clin Exp Allergy. 2008; 38:338-349. [PubMed: 18005184] 
8. Song DJ, Cho JY, Miller M, Strangman W, Zhang M, Varki A, Broide DH. Anti-Siglec-F antibody inhibits oral egg allergen induced intestinal eosinophilic inflammation in a mouse model. Clin Immunol. 2009; 131:157-169. [PubMed: 19135419]

9. van Odijk J, Peterson CGB, Ahlstedt S, Bengtsson U, Borres MP, Hulthén L, Magnusson J, Hansson T. Measurements of eosinophil activation before and after food challenges in adults with food hypersensitivity. Int Arch Allergy Immunol. 2006; 140:334-341. [PubMed: 16757922]

10. Pineton de Chambrun G, Desreumaux P, Cortot A. Eosinophilic enteritis. Dig Dis. 2015; 33:183189. [PubMed: 25925921]

11. Cianferoni A, Spergel JM. Eosinophilic esophagitis and gastroenteritis. Curr Allergy Asthma Rep. 2015; 15:58. [PubMed: 26233430]

12. Marichal T, Mesnil C, Bureau F. Homeostatic eosinophils: Characteristics and functions. Front Med. 2017; 4:101.

13. Mehta P, Furuta GT. Eosinophils in gastrointestinal disorders - eosinophilic gastrointestinal diseases, celiac disease, inflammatory bowel diseases and parasitic infections. Immunol Allergy Clin North Am. 2015; 35:413-437. [PubMed: 26209893]

14. Travers J, Rothenberg ME. Eosinophils in mucosal immune responses. Mucosal Immunol. 2015; 8:464-475. [PubMed: 25807184]

15. Chu DK, Jimenez-Saiz R, Verschoor CP, Walker TD, Goncharova S, Llop-Guevara A, Shen P, Gordon ME, Barra NG, Bassett JD, Kong J, Fattouh R, McCoy KD, Bowdish DM, Erjefalt JS, Pabst O, Humbles AA, Kolbeck R, Waserman S, Jordana M. Indigenous enteric eosinophils control DCs to initiate a primary Th2 immune response in vivo. J Exp Med. 2014; 211:1657-1672. [PubMed: 25071163]

16. Smith KM, Rahman RS, Spencer LA. Humoral immunity provides resident intestinal eosinophils access to luminal antigen via eosinophil-expressed low-affinity $\mathrm{Fc} \gamma$ receptors. J Immunol. 2016; 197:3716-3724. [PubMed: 27683752]

17. Uppal V, Kreiger P, Kutsch E. Eosinophilic gastroenteritis and colitis: a comprehensive review. Clin Rev Allergy Immunol. 2016; 50:175-188. [PubMed: 26054822]

18. Harris TR, Hammock BD. Soluble epoxide hydrolase: Gene structure, expression and deletion. Gene. 2013; 526:61-74. [PubMed: 23701967]

19. Morisseau C, Hammock BD. Impact of soluble epoxide hydrolase and epoxyeicosanoids on human health. Ann Rev Pharmacol Toxicol. 2013; 53:37-58. [PubMed: 23020295]

20. Zhang G, Kodani S, Hammock BD. Stabilized epoxygenated fatty acids regulate inflammation, pain, angiogenesis and cancer. Prog Lipid Res. 2014; 53:108-123. [PubMed: 24345640]

21. Bettaieb A, Chahed S, Bachaalany S, Griffey S, Hammock BD, Haj FG. Soluble epoxide hydrolase pharmacological inhibition ameliorates experimental acute pancreatitis in mice. Mol Pharmacol. 2015; 88:281-290. [PubMed: 25993999]

22. Zhang W, Yang AL, Liao J, Li H, Dong H, Chung YT, Bai H, Matkowskyj KA, Hammock BD, Yang GY. Soluble epoxide hydrolase gene deficiency or inhibition attenuates chronic active inflammatory bowel disease in IL-10(-/-) mice. Dig Dis Sci. 2012; 57:2580-2591. [PubMed: 22588244]

23. Yang J, Bratt J, Franzi L, Liu JY, Zhang G, Zeki AA, Vogel CFA, Williams K, Dong H, Lin Y, Hwang SH, Kenyon NJ, Hammock BD. Soluble epoxide hydrolase inhibitor attenuates inflammation and airway hyperresponsiveness in mice. Am J Respir Cell Mol Biol. 2015; 52:4655. [PubMed: 24922186]

24. Bauer RN, Manohar M, Singh AM, Jay DC, Nadeau KC. The future of biologics: Applications for food allergy. J Allergy Clin Immunol. 2015; 135:312-323. [PubMed: 25662303]

25. Patel BY, Volcheck GW. Food allergy: Common causes, diagnosis, and treatment. Mayo Clin Proc. 2015; 90:1411-1419. [PubMed: 26434966]

26. Meinlschmidt P, Sussmann D, Schweiggert-Weisz U, Eisner P. Enzymatic treatment of soy protein isolates: effects on the potential allergenicity, technofunctionality, and sensory properties. Food Sci Nutr. 2016; 4:11-23. [PubMed: 26788306]

27. Holzhauser T, Wackermann O, Ballmer-Weber BK, Bindslev-Jensen C, Scibilia J, Perono-Garoffo L, Utsumi S, Poulsen LK, Vieths S. Soybean (Glycine max) allergy in Europe: Gly m 5 (beta- 
conglycinin) and Gly m 6 (glycinin) are potential diagnostic markers for severe allergic reactions to soy. J Allergy Clin Immunol. 2009; 123:452-458. [PubMed: 18996574]

28. Wang T, Qin GX, Sun ZW, Zhao Y. Advances of research on glycinin and $\beta$-Conglycinin: A review of two major soybean allergenic proteins. Crit Rev Food Sci Nutr. 2014; 54:850-862. [PubMed: 24499064]

29. Leonard SA, Nowak-Wegrzyn A. Food protein-induced enterocolitis syndrome. Pediatr Clin North Am. 2015; 62:1463-1477. [PubMed: 26456444]

30. Liu X, Feng J, Xu ZR, Wang YZ, Liu JX. Oral allergy syndrome and anaphylactic reactions in BALB/c mice caused by soybean glycinin and $\beta$-conglycinin. Clin Exp Allergy. 2008; 38:350 356. [PubMed: 18070164]

31. Sun P, Li D, Li Z, Dong B, Wang F. Effects of glycinin on IgE-mediated increase of mast cell numbers and histamine release in the small intestine. J Nutr Biochem. 2008; 19:627-633. [PubMed: 18280135]

32. Taliercio E, Loveless TM, Turano MJ, Kim SW. Identification of epitopes of the $\beta$ subunit of soybean $\beta$-conglycinin that are antigenic in pigs, dogs, rabbits and fish. J Sci Food Agric. 2014; 94:2289-2294. [PubMed: 24415270]

33. Walter J, Greenberg Y, Sriramarao P, Ismail BP. Limited hydrolysis combined with controlled Maillard-induced glycation does not reduce immunoreactivity of soy protein for all sera tested. Food Chem. 2016; 213:742-752. [PubMed: 27451243]

34. Rajavelu P, Rayapudi M, Moffitt M, Mishra A, Mishra A. Significance of para-esophageal lymph nodes in food or aeroallergen-induced iNKT cell-mediated experimental eosinophilic esophagitis. Am J Physiol Gastrointest Liver Physiol. 2012; 302:G645-G654. [PubMed: 22207581]

35. Hwang SH, Tsai HJ, Liu JY, Morisseau C, Hammock BD. Orally bioavailable potent soluble epoxide hydrolase inhibitors. J Med Chem. 2007; 50:3825-3840. [PubMed: 17616115]

36. Wagner K, Yang J, Inceoglu B, Hammock BD. Soluble epoxide hydrolase inhibition is antinociceptive in a mouse model of diabetic neuropathy. J Pain. 2014; 15:907-914. [PubMed: 24924124]

37. Ge XN, Ha SG, Greenberg YG, Rao A, Bastan I, Blidner AG, Rao SP, Rabinovich GA, Sriramarao P. Regulation of eosinophilia and allergic airway inflammation by the glycan-binding protein galectin-1. Proc Natl Acad Sci USA. 2016; 113:E4837-E4846. [PubMed: 27457925]

38. Vaali K, Lappalainen J, Lin AH, Mäyränpää MI, Kovanen PT, Berstad A, Eklund KK. Imatinib mesylate alleviates diarrhea in a mouse model of intestinal allergy. Neurogastroenterol Motil. 2012; 24:e325-e335. [PubMed: 22709239]

39. Abramoff MD, Magalhaes PJ, Ram SJ. Image Processing with ImageJ. Biophotonics International. 2004; 11:36-42.

40. Sakamoto K, Hirose H, Onizuka A, Hayashi M, Futamura N, Kawamura Y, Ezaki T. Quantitative study of changes in intestinal morphology and mucus gel on total parenteral nutrition in rats. $\mathrm{J}$ Surg Res. 2000; 94:99-106. [PubMed: 11104649]

41. Bahaie NS, Kang B, Frenzel EM, Hosseinkhani MR, Ge X, Greenberg Y, Ha S, Demetriou M, Rao SP, Sriramarao P. N-glycans differentially regulate eosinophil and neutrophil recruitment during allergic airway inflammation. J Biol Chem. 2011; 286:38231-38241. [PubMed: 21911487]

42. Dyer KD, Moser JM, Czapiga M, Siegel SJ, Percopo CM, Rosenberg HF. Functionally competent eosinophils differentiated ex vivo in high purity from normal mouse bone marrow. J Immunol. 2008; 181:4004-4009. [PubMed: 18768855]

43. Schmelzer KR, Kubala L, Newman JW, Kim IH, Eiserich JP, Hammock BD. Soluble epoxide hydrolase is a therapeutic target for acute inflammation. Proc Natl Acad Sci USA. 2005; 102:9772-9777. [PubMed: 15994227]

44. Ayush S, Krishnamurthy PT, Pooja T, Hammock BD, Hwang SH. Soluble epoxide hydrolase inhibitor, $t$-TUCB, protects against myocardial ischemic injury in rats. J Pharm Pharmacol. 2014; 66:1251-1258. [PubMed: 24697323]

45. Evans CM, Kim K, Tuvim MJ, Dickey BF. Mucus hypersecretion in asthma: causes and effects. Curr Opin Pulm Med. 2009; 15:4-11. [PubMed: 19077699] 
46. Saldanha JC, Gargiulo DL, Silva SS, Carmo-Pinto FH, Andrade MC, Alvarez-Leite JI, Teixeira MM, Cara DC. A model of chronic IgE-mediated food allergy in ovalbumin-sensitized mice. Braz J Med Biol Res. 2004; 37:809-816. [PubMed: 15264023]

47. Turner JR. Intestinal mucosal barrier function in health and disease. Nat Rev Immunol. 2009; 9:799-809. [PubMed: 19855405]

48. Draper AJ, Hammock BD. Soluble epoxide hydrolase in rat inflammatory cells is indistinguishable from soluble epoxide hydrolase in rat liver. Toxicol Sci. 1999; 50:30-35. [PubMed: 10445750]

49. Perrier C, Corthésy B. Gut permeability and food allergies. Clinical \& Experimental Allergy. 2011; 41:20-28. [PubMed: 21070397]

50. Yu LCH. Intestinal epithelial barrier dysfunction in food hypersensitivity. J Allergy. 2012; 2012:596081.

51. Konig J, Wells J, Cani PD, Garcia-Rodenas CL, MacDonald T, Mercenier A, Whyte J, Troost F, Brummer RJ. Human intestinal barrier function in health and disease. Clin Transl Gastroenterol. 2016; 7:e196. [PubMed: 27763627]

52. Zhang W, Li H, Dong HUA, Liao JIE, Hammock BD, Yang GY. Soluble epoxide hydrolase deficiency inhibits dextran sulfate sodium-induced colitis and carcinogenesis in mice. Anticancer Res. 2013; 33:5261-52711. [PubMed: 24324059]

53. Panigrahy D, Kalish BT, Huang S, Bielenberg DR, Le HD, Yang J, Edin ML, Lee CR, Benny O, Mudge DK, Butterfield CE, Mammoto A, Mammoto T, Inceoglu B, Jenkins RL, Simpson MA, Akino T, Lih FB, Tomer KB, Ingber DE, Hammock BD, Falck JR, Manthati VL, Kaipainen A, D'Amore PA, Puder M, Zeldin DC, Kieran MW. Epoxyeicosanoids promote organ and tissue regeneration. Proc Natl Acad Sci USA. 2013; 110:13528-13533. [PubMed: 23898174]

54. Gao Y, Feng J, Ma K, Zhou Z, Zhu Y, Xu Q, Wang X. 8,9-Epoxyeicosatrienoic acid inhibits antibody production of B lymphocytes in mice. PLoS ONE. 2012; 7:e40258. [PubMed: 22802958]

55. Jung Y, Rothenberg ME. Roles and regulation of gastrointestinal eosinophils in immunity and disease. J Immunol. 2014; 193:999-1005. [PubMed: 25049430]

56. Hogan SP. Functional Role of Eosinophils in gastrointestinal inflammation. Immunol Allergy Clin North Am. 2009; 29:129-140. [PubMed: 19141348]

57. Furuta GT, Nieuwenhuis EES, Karhausen J, Gleich G, Blumberg RS, Lee JJ, Ackerman SJ. Eosinophils alter colonic epithelial barrier function: role for major basic protein. Am J Physiol Gastrointest Liver Physiol. 2005; 289:G890-G897. [PubMed: 16227527]

58. Mishra A, Hogan SP, Lee JJ, Foster PS, Rothenberg ME. Fundamental signals that regulate eosinophil homing to the gastrointestinal tract. J Clin Invest. 1999; 103:1719-1727. [PubMed: 10377178]

59. Bischoff SC, Mayer J, Wedemeyer J, Meier PN, Zeck-Kapp G, Wedi B, Kapp A, Cetin Y, Gebel M, Manns MP. Colonoscopic allergen provocation (COLAP): a new diagnostic approach for gastrointestinal food allergy. Gut. 1997; 40:745-753. [PubMed: 9245928]

60. Bischoff SC. Physiological and pathophysiological functions of intestinal mast cells. Semin Immunopathol. 2009; 31:185-205. [PubMed: 19533134]

61. Groschwitz KR, Ahrens R, Osterfeld H, Gurish MF, Han X, Abrink M, Finkelman FD, Pejler G, Hogan SP. Mast cells regulate homeostatic intestinal epithelial migration and barrier function by a chymase/Mcpt4-dependent mechanism. Proc Natl Acad Sci USA. 2009; 106:22381-22386. [PubMed: 20018751]

62. Iyer A, Kauter K, Alam MA, Hwang SH, Morisseau C, Hammock BD, Brown L. Pharmacological inhibition of soluble epoxide hydrolase ameliorates diet-induced metabolic syndrome in rats. Exp Diabetes Res. 2016; 2012:758614.

63. Johansson MEV, Hansson GC. Immunological aspects of intestinal mucus and mucins. Nat Rev Immunol. 2016; 16:639-649. [PubMed: 27498766]

64. Martinez-Maqueda D, Miralles B, De Pascual-Teresa S, Reveron I, Munoz R, Recio I. Foodderived peptides stimulate mucin secretion and gene expression in intestinal cells. J Agric Food Chem. 2012; 60:8600-8605. [PubMed: 22916966]

65. Plaisancie P, Boutrou R, Estienne M, Henry G, Jardin J, Paquet A, Leonil J. $\beta$-Casein (94-123)derived peptides differently modulate production of mucins in intestinal goblet cells. J Dairy Res. 2015; 82:36-46. [PubMed: 25335546] 
66. Suzuki T. Regulation of intestinal epithelial permeability by tight junctions. Cell Mol Life Sci. 2013; 70:631-659. [PubMed: 22782113]

67. McDermott JR, Bartram RE, Knight PA, Miller HRP, Garrod DR, Grencis RK. Mast cells disrupt epithelial barrier function during enteric nematode infection. Proc Natl Acad Sci USA. 2003; 100:7761-7766. [PubMed: 12796512]

68. Pizzuti D, Senzolo M, Buda A, Chiarelli S, Giacomelli L, Mazzon E, Curioni A, Faggian D, De Lazzari F. In vitro model for IgE mediated food allergy. Scand J Gastroenterol. 2011; 46:177-187. [PubMed: 21028948]

69. Moghaddam MF, Grant DF, Cheek JM, Greene JF, Williamson KC, Hammock BD. Bioactivation of leukotoxins to their toxic diols by epoxide hydrolase. Nat Med. 1997; 3:562-566. [PubMed: 9142128]

70. Sanders WG, Morisseau C, Hammock BD, Cheung AK, Terry CM. Soluble epoxide hydrolase expression in a porcine model of arteriovenous graft stenosis and anti-inflammatory effects of a soluble epoxide hydrolase inhibitor. Am J Physiol Cell Physiol. 2012; 303:C278-C290. [PubMed: 22621785]

71. Sun J, Sui X, Bradbury JA, Zeldin DC, Conte MS, Liao JK. Inhibition of vascular smooth muscle cell migration by cytochrome p450 epoxygenase-derived eicosanoids. Circ Res. 2002; 90:10201027. [PubMed: 12016269]

72. Feng W, Xu X, Zhao G, Li G, Liu T, Zhao J, Ruolan D, Dao WW, Tu L. EETs and CYP2J2 inhibit TNF- $\alpha$-induced apoptosis in pulmonary artery endothelial cells and TGF- $\beta 1$-induced migration in pulmonary artery smooth muscle cells. Int J Mol Med. 2013; 32:685-693. [PubMed: 23835530]

73. Kundu S, Roome T, Bhattacharjee A, Carnevale KA, Yakubenko VP, Zhang R, Hwang SH, Hammock BD, Cathcart MK. Metabolic products of soluble epoxide hydrolase are essential for monocyte chemotaxis to MCP-1 in vitro and in vivo. J Lipid Res. 2013; 54:436-447. [PubMed: 23160182]

74. Boehme SA, Sullivan SK, Crowe PD, Santos M, Conlon PJ, Sriramarao P, Bacon KB. Activation of mitogen-activated protein kinase regulates eotaxin- induced eosinophil migration. J Immunol. 1999; 163:1611-1618. [PubMed: 10415066]

75. Choi EN, Choi MK, Park CS, Chung IY. A parallel signal-transduction pathway for eotaxin- and interleukin-5-induced eosinophil shape change. Immunol. 2003; 108:245-256.

76. Duan W, Chan JHP, Wong CH, Leung BP, Wong WSF. Anti-inflammatory effects of mitogenactivated protein kinase kinase inhibitor U0126 in an asthma mouse model. J Immunol. 2004; 172:7053-7059. [PubMed: 15153527]

77. Rothenberg ME, Ownbey R, Mehlhop PD, Loiselle PM, van de Rijn M, Bonventre JV, Oettgen $\mathrm{HC}$, Leder P, Luster AD. Eotaxin triggers eosinophil-selective chemotaxis and calcium flux via a distinct receptor and induces pulmonary eosinophilia in the presence of interleukin 5 in mice. Mol Med. 1996; 2:334-348. [PubMed: 8784786]

78. Bahaie NS, Hosseinkhani RM, Ge XN, Kang BN, Ha SG, Blumenthal MN, Jessberger R, Rao SP, Sriramarao P. Regulation of eosinophil trafficking by SWAP-70 and its role in allergic airway inflammation. J Immunol. 2012; 188:1479-1490. [PubMed: 22210919]

79. Tsai FC, Kuo GH, Chang SW, Tsai PJ. Ca2+ Signaling in cytoskeletal reorganization, cell migration, and cancer metastasis. Biomed Res Int. 2015; 2015:13.

80. Fang X, Weintraub NL, Stoll LL, Spector AA. Epoxyeicosatrienoic acids increase intracellular calcium concentration in vascular smooth muscle cells. Hypertension. 1999; 34:1242-1246. [PubMed: 10601125]

81. Pratt PF, Rosolowsky M, Campbell WB. Effects of epoxyeicosatrienoic acids on polymorphonuclear leukocyte function. Life Sci. 2002; 70:2521-2533. [PubMed: 12173415] 


\section{Summary Sentence}

Soy protein-induced soluble epoxide hydrolase promotes allergic responses, gastrointestinal inflammation and eosinophilia; pharmacological inhibition of this enzyme leads to attenuation of these responses. 
A

SPI (200 $\mu \mathrm{g}$ with $1 \mathrm{mg}$ alum hydroxide) or alum hydroxide alone,

$200 \mu l$, i.p

- SPI (100 $\mu \mathrm{g})$ or saline, $100 \mu \mathrm{l}$, gavage

$\downarrow t$-TUCB ( $1 \mathrm{mg} / \mathrm{kg}$ or $3 \mathrm{mg} / \mathrm{kg}$ bodyweight) or saline,

$2 \mathrm{~h}$ before challenge, gavage,

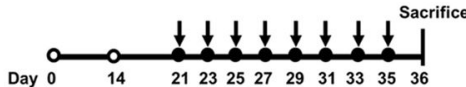

c

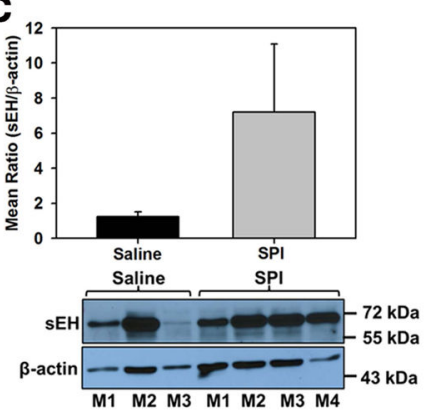

B

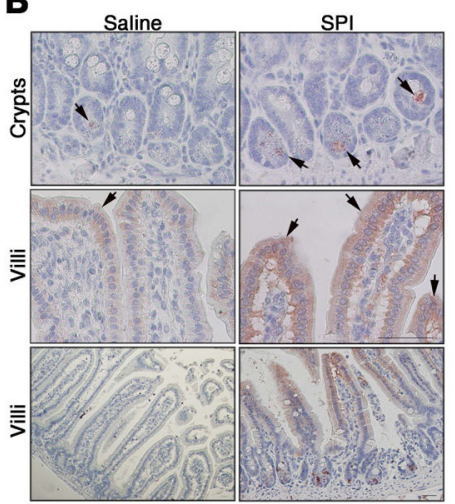

Fig. 1. Oral exposure to SPI increases expression of intestinal sEH

(A) Outline of protocol for SPI-induced intestinal inflammation in mice. i.p; intraperitoneal. (B) sEH expression in the crypts and villi of control and SPI-challenged mice assessed by immunohistology with polyclonal anti-sEH antibody (stained reddish brown) at high magnification (top and middle panels) and low magnification (bottom panels). Arrows indicate staining in the epithelium and crypts. Data representative of $n=4-6$ mice/group are shown. Scale bar, $50 \mu \mathrm{m}$. (C) sEH expression in the jejunum of control and SPI-challenged mice by densitometric analysis of Western blots. A representative Western blot is shown below graph. M1-M4 represents different mice in each group. Combined data (Mean \pm SEM) for $\mathrm{n}=4$ mice for control and 7 mice for SPI group are shown in C. 

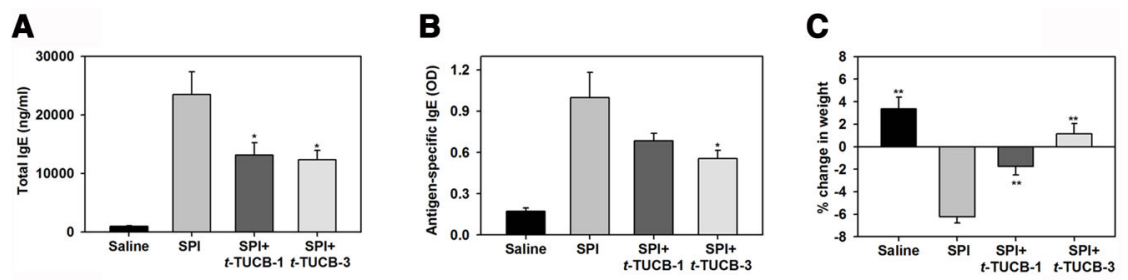

Fig. 2. Attenuation of SPI-induced IgE and weight loss by inhibition of SEH with $\boldsymbol{t}$-TUCB (A and B) Total and SPI-specific IgE levels in the serum of control and SPI-challenged mice with and without $t$-TUCB treatment. (C) Change in weight of control and SPI-challenged mice with and without $t$-TUCB treatment. Combined data (Mean \pm SEM) of $\mathrm{n}=8-12$ mice/ group are shown. $* \mathrm{p}<0.05$ in $\mathrm{A}$ and $\mathrm{B}$ and $* * \mathrm{p}<0.01$ in $\mathrm{C}$ versus SPI. 
A

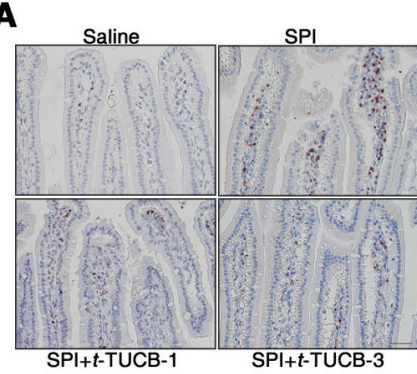

D

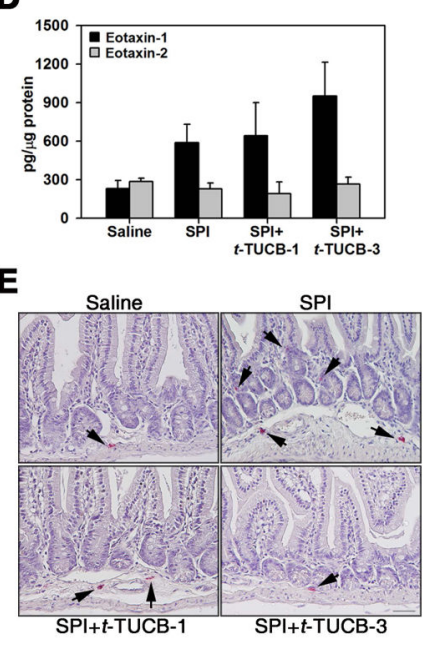

B

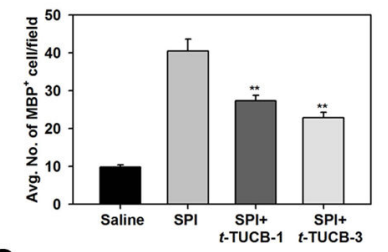

C

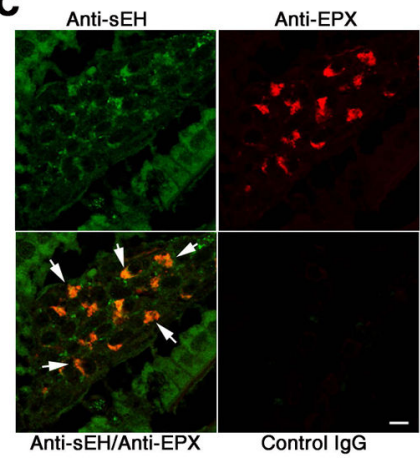

$\mathbf{F}$

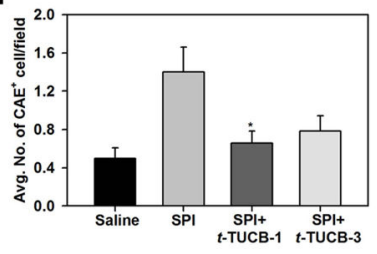

Fig. 3. Effect of $t$-TUCB on recruitment of eosinophils and mast cells in the jejunum of SPIchallenged mice

(A) Eosinophils in the jejunum of control and SPI-challenged mice with and without $t$ TUCB treatment assessed by immunohistology with rat mAb against MBP (stained dark brown). A representative image is shown for each group. (B) Quantitation of cells positive for expression of MBP in the villi of the above groups of mice. (C) Eotaxin-1 and 2 levels in jejunal tissue lysates of control and SPI-challenged mice with and without $t$-TUCB treatment by ELISA. (D) Dual immunostaining of jejunal sections from SPI-challenged mice with antibodies against sEH (green) and eosinophil-specific EPX (red). Arrows indicate sEH-positive/EPX-positive cells in the villi. Immunoreactivity in jejunal sections treated with control IgG is also shown. Data representative of 3 mice are shown. (E) Prevalence of mast cells in control and SPI-challenged mice with and without $t$-TUCB treatment based on CAE staining (stained dark purple). Arrows indicate CAE-positive cells. A representative image is shown for each group. (F) Quantitation of CAE-positive cells in the lower lamina propria of the above groups of mice. Scale bar, $100 \mu \mathrm{m}$ in A and E, $20 \mu \mathrm{m}$ in C. Combined data (mean \pm SEM) of $n=9-12$ mice/group in $B$ and $F$ and 6-8 mice/group in $\mathrm{D}$ are shown. ${ }^{* *} \mathrm{p}<0.01$ in $\mathrm{B}$ and $* \mathrm{p}<0.05$ in F versus SPI. 
A

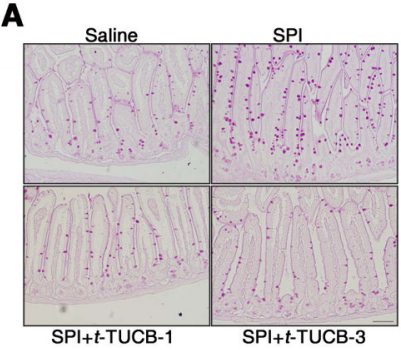

C

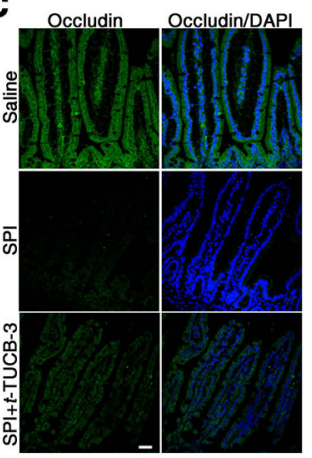

B

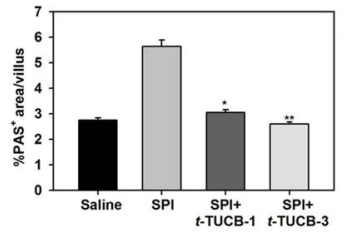

D

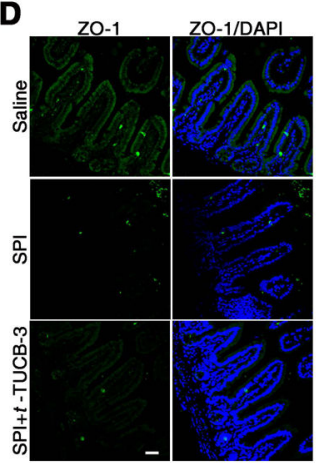

E

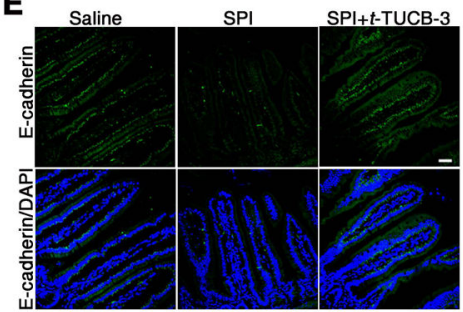

Fig. 4. Effect of $t$-TUCB on mucus secretion and epithelial barrier integrity in the jejunum of SPI-challenged mice

(A) Mucus secretion in the villi of control and SPI-challenged mice with and without $t$ TUCB treatment assessed by PAS staining (stained dark-pink). A representative image is shown for each group. (B) Quantitation of PAS-positive area in the villi of the above groups of mice. (C-E) Occludin, ZO-1 and E-cadherin expression in control and SPI-challenged mice with and without $t$-TUCB treatment by immunofluoresecent staining with specific antibodies. Scale bar, $200 \mu \mathrm{m}$ in A, $30 \mu \mathrm{m}$ in C-E. Data representative of $\mathrm{n}=3-5$ mice/group are shown in C-E. Combined data (mean \pm SEM) of $n=9-12$ mice/group are shown in B. $* \mathrm{p}<0.05$ and $* * \mathrm{p}<0.01$ versus SPI. 
A

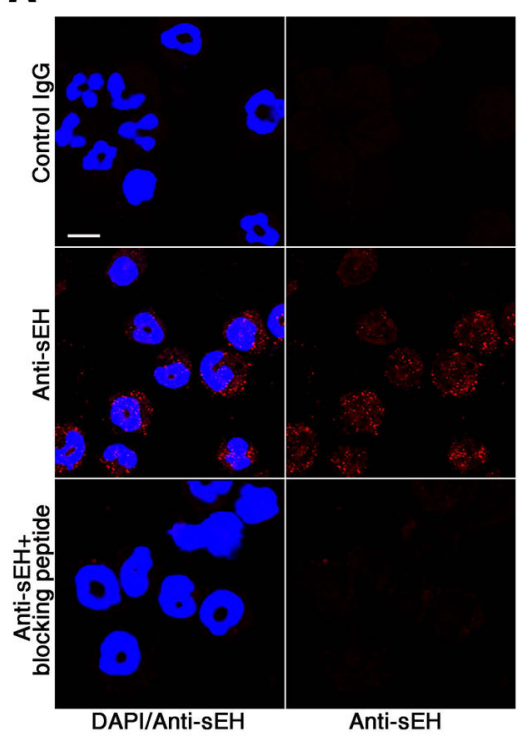

B

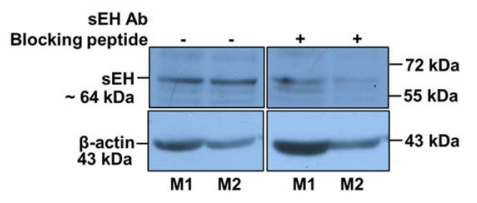

C
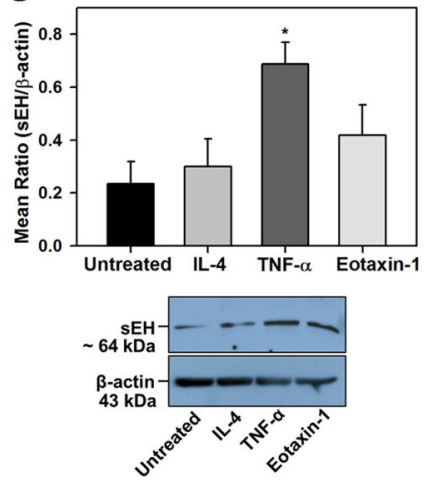

Fig. 5. Murine eosinophils express sEH

(A) Expression of sEH in permeabilized eosinophils by immunofluorescence staining with anti-sEH in the absence and presence of sEH antibody blocking peptide. Immunoreactivity with normal goat IgG is shown as a control. Scale bar, $10 \mu \mathrm{m}$. (B) Expression of sEH in lysates of murine BM eosinophils by Western blot analysis with anti-sEH. Expression in lysates of two representative mice (M1 and M2) in the absence and presence of sEH antibody blocking peptide is shown. (C) Effect of inflammatory cytokines on sEH expression by eosinophils. Cells cultured in medium alone or in medium containing murine $\mathrm{IL}-4, \mathrm{TNFa}$ or eotaxin- 1 for $24 \mathrm{~h}$ at $37^{\circ} \mathrm{C}$ were analyzed for sEH expression by Western blot followed by densitometric analysis. A representative Western blot is shown below graph in C. Combined data (mean $\pm \mathrm{SEM}$ ) of four experiments with eosinophils from different mice is shown in $C$. $* \mathrm{p}<0.05$ versus untreated cells. 
A

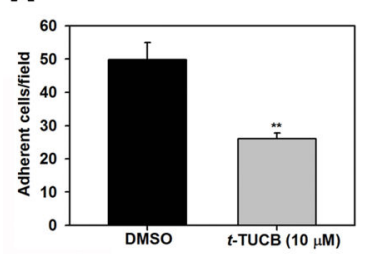

C

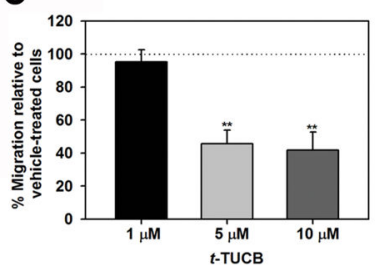

B

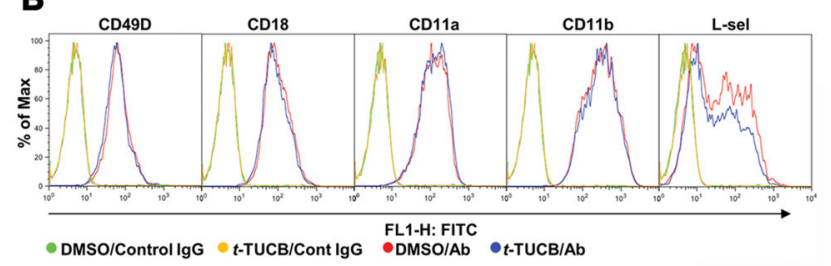

D

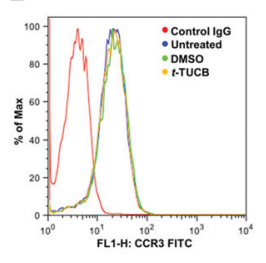

E

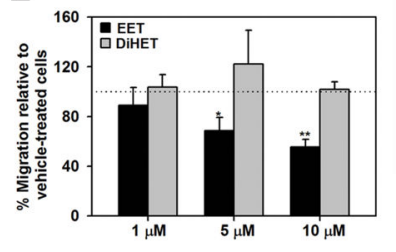

Fig. 6. $t$-TUCB inhibits eosinophil adhesion and migration

(A) Adhesion of eosinophils treated with $10 \mu \mathrm{M} t$-TUCB $\left(30 \mathrm{~min}\right.$ at $\left.37^{\circ} \mathrm{C}\right)$ or vehicle alone to VCAM-1-coated cover-slips. The number of adherent cells was determined after $30 \mathrm{~min}$. (B) Analysis of adhesion molecule expression in eosinophils treated with $t$-TUCB (as described above) by flow cytometry with the indicated antibodies. (C) Migration of eosinophils treated with $t$-TUCB at the indicated doses or vehicle alone (as in A) towards eotaxin-1 (100 nM) in Transwell ${ }^{\circledR}$ plates. The number of migrated cells in the lower wells was determined. (D) Expression of CCR3 in eosinophils treated with $t$-TUCB $(5 \mu \mathrm{M})$ by flow cytometry with rat anti-mouse CCR3. (E) Migration of eosinophils treated with the indicated doses of 11,12-EET and 11,12-DiHET or vehicle alone towards eotaxin-1 in Transwell ${ }^{\circledR}$ plates. Combined data (Mean \pm SEM) of three experiments in duplicate are shown in A, C and E. Representative data of three independent experiments with eosinophils from different mice are shown in $\mathrm{B}$ and $\mathrm{D} .{ }^{*} \mathrm{*} p<0.01$ and $* \mathrm{p}<0.05$ versus corresponding vehicle-treated cells. 
A

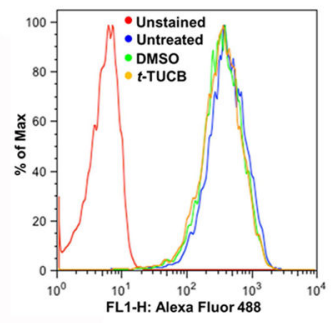

B

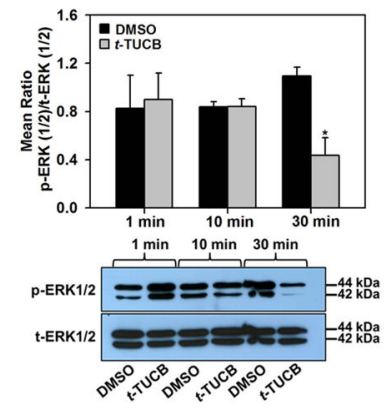

C

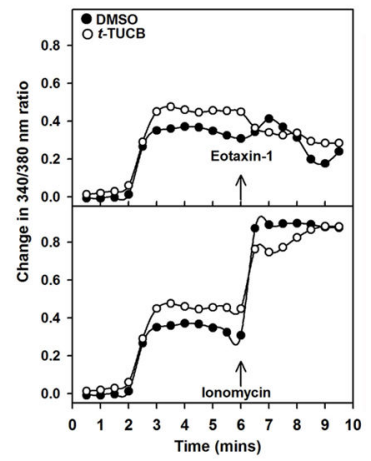

Fig. 7. $t$-TUCB inhibits ERK (1/2) activation and eotaxin-1-induced calcium flux in eosinophils (A) Expression of total F-actin levels in eosinophils treated with $t$-TUCB $(5 \mu \mathrm{M})$ by flow cytometry with Alexa Fluor 488 Phalloidin. Representative data of three independent experiments with eosinophils from different mice are shown. (B) ERK (1/2) phosphorylation in eosinophils treated with $5 \mu \mathrm{M} t$-TUCB or vehicle alone up to $30 \mathrm{~min}$ and analyzed for expression of total and phosphorylated levels of ERK (1/2) by Western blot analysis. t-ERK, total ERK (1/2); p-ERK, phosphorylated ERK (1/2). A representative Western blot is shown below graph. (C) $\left[\mathrm{Ca}^{2+}\right]_{\mathrm{i}}$ levels in eosinophils treated with $5 \mu \mathrm{M} t$-TUCB or vehicle followed by eotaxin-1 (upper panel) or ionomycin (lower panel) by digital videofluorescence imaging using the $\mathrm{Ca}_{2}{ }^{+}$indicator dye Fura-2 AM. Combined data (Mean \pm SEM) of three or more experiments in $\mathrm{B}$ and $\mathrm{C}$ are shown. In $\mathrm{C}$, pooled data of $>200$ cells are shown for DMSOand $t$-TUCB-treated condition. ${ }^{*} \mathrm{p}<0.05$ versus vehicle-treated cells in B. 